\title{
SPINOZA: O SUJEITO OCULTO DAS DISPUTAS ENTRE ILUMINISTAS RADICAIS E MODERADOS NA FUNDAÇÃO DOS $\mathrm{EUA}^{1}$
}

\author{
Francisco de Guimaraens ${ }^{2}$
}

\begin{abstract}
REsumo: Este trabalho analisa uma questão pouco explorada sobre o processo de formação da federação e da república dos EUA, ao final do século XVIII. Trata-se da presença de teses spinozanas nos debates que conduziram tal processo. Para demonstrar essa presença, o trabalho se valerá do cenário apresentado por Jonathan Israel, no qual se verifica uma divisão entre radicais e moderados, dentro do próprio iluminismo, e o protagonismo de Spinoza na formação do iluminismo radical. Esse conflito teria alcançado os EUA justamente no período que envolveu a independência das treze colônias inglesas e os anos subsequentes à fundação constitucional dos EUA.
\end{abstract}

Palavras-chave: Spinoza. Iluminismo. Constituição dos EUA.

\section{INTRODUÇÃo}

Há uma lacuna na história do pensamento político a enfrentar: a presença de Spinoza nos debates políticos do mundo anglo-saxão, sobretudo durante o processo de formação dos EUA. Por essa razão, este trabalho apresentará alguns dados relevantes, tanto de natureza historiográfica quanto de ordem conceitual, a fim de abrir caminhos de investigação desse tema.

É de se estranhar a ausência de trabalhos sobre o tema, como se Spinoza não houvesse alcançado o outro lado do Atlântico Norte. É improvável a inexistência de penetração do spinozismo nos EUA, se documentos demonstram que aos autores de referência para os pais fundadores, como Locke e Montesquieu, sofreram acusaçóes de spinozismo por parte de seus contemporâneos ou, ainda, quando se percebe a incorporaçáo explícita de teses spinozanas por autores de relevância notória para a formação dos mesmos pais fundadores, como Toland e Bolingbroke. Tăo mais improvável é o desconhecimento das teses de Spinoza, se,

\footnotetext{
${ }^{1}$ http://dx.doi.org/10.1590/S0101-31732018000100007

2 Professor do Programa de Pós-Graduação em Direito e do Curso de Graduaçáo em Direito da PUC-Rio, Diretor do Departamento de Direito da PUC-Rio, Rio de Janeiro, RJ - Brasil. E-mail: chicodeguima@puc-rio.br; chicodeguima@gmail.com
}

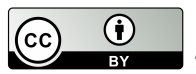

This is an open-access article distributed under the terms of the Creative Commons Attribution License. 
no período pré e pós-revolucionário, ocorreu significativa circulação de refutaçôes das mesmas, através das obras de Leibniz, Clarke e de Bayle.

Tal variedade de indícios da incorporação do spinozismo à reflexão política, durante a fundação dos EUA, justifica o estudo do tema. Para atingir o objetivo de jogar luz sobre o sujeito oculto dos debates políticos, este trabalho investigará as pistas da presença de Spinoza, desde o período pré-revolucionário até a década posterior à formação constitucional da federação, e percorrerá as seguintes etapas: a) exposição da análise contemporânea do modo singular de difusão do spinozismo, pois a censura e as ameaças que atingiam os difusores de seu pensamento forçaram a invenção de métodos heterodoxos de circulação do sistema de Spinoza, como a refutação; b) apresentação de elementos da formação intelectual de Madison, Jefferson e Thomas Paine que evidenciam o conhecimento, por esses autores, da obra de Spinoza; c) demonstração da origem spinozana de duas noçóes lockeanas (as verdades autoevidentes e a busca pela felicidade) incorporadas por Thomas Jefferson, na Declaração de Independência; d) os efeitos, nos EUA, das disputas europeias entre iluministas radicais, profundamente influenciados por Spinoza, segundo Jonathan Israel, e iluministas moderados.

\section{Sobre O MÉTOdo DE INVESTIGAÇÁo DA DIFUSÃo do SPINOZISMO}

A absorção de Spinoza por seus contemporâneos e, no século XVIII, século posterior à sua morte, ocorrida em 1677, por vezes não é demonstrável por explícitas citaçôes ou por uma incorporação que poderíamos chamar de fidedigna. A circulação de seu pensamento padeceu de notórias dificuldades. Sua única obra publicada em vida, em 1670, o Tratado teológico-político, foi censurada pelas Províncias Unidas dos Países Baixos, em 1674, dois anos após a queda da república, sucedendo-se o mesmo com suas obras completas, publicadas post mortem, em 1677. A proibição estatal se deu paralelamente à proibição teológica, na medida em que os sínodos da Reforma vetaram a publicaçáo e a leitura de escritos de Spinoza (KLEVER, 2012b, p. 73). Por tais razóes, durante muito tempo, sua obra foi impressa e difundida com falsos títulos e nomes fictícios de autores (KLEVER, 2012b, p. 73).

Outro modo comum, e certamente muito peculiar, de propagação da filosofia de Spinoza envolveu as próprias refutações de Spinoza. Em virtude da proibição de leitura e de circulação de seus escritos, era mais fácil chegar a Spinoza por meio de seus refutadores, cujas obras possuíam três finalidades dis- 
tintas: dissimulação da adesão ao spinozismo, objeção teórica ou denúncia do sistema spinozano (CITTON, 2007, p. 310). Ou seja, até entre os refutadores de Spinoza, havia aqueles que aderiram a seu sistema. A prudência sugere não tomar as refutaçóes a Spinoza ao pé da letra. Sua análise deve considerar a produção filosófica dos refutadores de Spinoza para, somente então, encontrar-se a real finalidade da refutação.

Em outros exemplos de absorção, é ainda mais difícil demonstrar a presença de Spinoza do que nas refutaçóes produzidas por adeptos do spinozismo. O caso de John Locke, cujo spinozismo dissimulado sequer rendeu refutação pública da parte do autor inglês, se enquadra nessa hipótese. Wim Klever explicita a associação entre as teses lockeanas e as spinozanas e salienta os ecos spinozanos nos seguintes temas investigados por Locke: a formaçáo da ordem política pelo consenso; a ideia de que o direito natural não cessa após a instituição do direito civil; a exigência de efetividade para conquista da legitimidade do exercício do direito de resistência (um direito só vale ao ser exercido, ao se tornar realidade); a questão da tolerância (KLEVER, 2012b, p. 67-73). As semelhanças das teses e também do estilo de Locke e de Spinoza, comprovado pela repetição, por Locke, de expressóes spinozanas, são indícios fortes do dissimulado spinozismo lockeano.

Há, portanto, uma questáo de método a enfrentar, quando se trata de investigar e de desvendar a penetração da filosofia de Spinoza, no século XVII e no século XVIII. Se sua filosofia foi proscrita durante muito tempo, se era arriscado declarar-se spinozista nos séculos XVII e XVIII e se o acesso às teses de Spinoza acontecia, normalmente, por intermédio de refutaçóes de sua obra, exige-se um método mais sofisticado do que a mera demonstração da apropriação explícita de sua filosofia pelos autores do século XVII e do século XVIII.

A ideia de apropriação ou de influência de uma filosofia sobre outra se assemelha à circulação de fluidos, conforme explica Yves Citton (2007, p. 322). Quando se busca uma adesão explícita ou ao menos atestável de um autor a uma determinada filosofia, deixa-se na penumbra todo tipo de efeito que uma filosofia proscrita, qual a de Spinoza, produziu ao longo da história do pensamento. Ao invés do modelo de circulação de fluidos, o qual serve de inspiração para as análises de recepção que levam em consideração "[...] contatos diretos, as relaçôes de continuidade, as citaçôes e as referências explícitas, os acordos de princípios, as convergências conscientes" (CITTON, 2007, p. 309), Citton propóe o modelo dos efeitos de ressonância. Os efeitos de ressonância se distinguem da circulação de fluidos em dois sentidos: a) inexiste uma relação de subordinação 
teórica e conceitual entre o autor que promove a inovação e o outro que a copia (CITTON, 2007, p. 309); b) a "continuidade da influência" define a circulação de fluidos, enquanto a "contiguidade da invenção" caracteriza o modelo de ressonância (CITTON, 2007, p. 322). Segundo o autor, a difusão do spinozismo na França aconteceu mediante um processo de invençáo coletiva, que partia das teses de Spinoza, para reconstruir o sentido dessas mesmas teses, de acordo com as circunstâncias distintas de absorção do sistema spinozano. Essa perspectiva da produção do spinozismo, fundada no modelo de ressonância, não se limitou à França, porém, se expandiu por toda a Europa e chegou até o outro lado do Atlântico Norte, conforme demonstra Jonathan Israel, nas obras Radical enlightenment e Democratic enlightenment. Se, no modelo de circulação de fluidos, as ideias exprimem uma identidade a ser absorvida pelo receptor, no modelo de ressonância, uma ideia equivale à vibração de uma corda, transmitida a outra em uma relação harmônica (CITTON, 2007, p. 322), que não exclui a singularidade de nenhuma das cordas da relação.

$\mathrm{O}$ modelo da ressonância não diz respeito à demonstração de incorporação ou influência das teses de um autor, mas à ideia de que o movimento contínuo de reinvenção de um certo sistema filosófico concerne à literatura e se constitui em um processo coletivo de escritura de um sistema filosófico (CITTON, 2007, p. 320). Deleuze, quando aborda a relação entre D. H. Lawrence, que sequer filósofo era, e Nietzsche, apresenta noção semelhante à de Citton, ao afirmar que Lawrence apanha uma flecha lançada por Nietzsche e a relança, em outra direção (DELEUZE, 2004, p. 46). Náo se trata de uma imitação, mas justamente de um efeito de ressonância, de uma nova modalização da vibraçáo de uma corda, de uma nova expressão de um determinado conceito. Isso se deu durante a produção do spinozismo. Os irmãos Koerbargh, Bayle, Boulainvilliers, Locke, Diderot, Goethe, Jacobi, Mendelssohn, Holbach e tantos outros pensadores dos séculos XVII e XVIII participaram desse efeito de ressonância do pensamento de Spinoza.

Citton entende que, para o modelo da ressonância, a produção conceitual equivale a um rizoma, e não a uma árvore, que detém uma unidade. A produção intelectual opera mediante um regime de multiplicidade inventiva, e não de uma repetição terminológica e de um mimetismo conceitual, os quais apenas reforçam um determinado sistema, mas não lhe acrescentam um novo sentido (CITTON, 2007, p. 311). Além disso, o modelo da ressonância possui uma vantagem: 
Enquanto um fluido que passa de A para B não pode alimentar o segundo recipiente sem se perder pelo primeiro, o conhecimento pode constituirse em objeto de uma cena comum, porque eu posso comunicá-lo a outro sem perdê-lo - da mesma forma que a corda que faz vibrar uma outra em uma relação harmônica não perde nada da vibração que ela partilha. (CITTON, 2007, p. 322).

Em suma, o modelo da ressonância, apesar de não anular e de não recusar a demonstração da influência e a incorporação explícita - tão difícil quanto rara, naqueles tempos em que livres pensadores corriam muito risco - de um autor por outro, é mais adequado à análise dos assuntos relativos ao pensamento, na medida em que os conceitos náo se perdem nem se repetem, mas se modificam continuamente, conservando a vibraçáo inicial dos sistemas com os quais guardam relação. A produção conceitual, portanto, diz respeito mais a um emaranhado de cordas, que vibram e transmitem suas vibraçóes, do que à circulação de um fluido. Se esse tipo de difusão de uma filosofia persiste ainda hoje, exerceu papel ainda mais relevante na propagação de teses filosóficas em tempos de proibição teológica e política do contato com determinadas filosofias tidas por heréticas e subversivas, como foi a de Spinoza.

\section{SPINOZA E AS DISPUTAS ENTRE AS LUZES RADICAIS E MODERADAS NOS EUA: o ELO PERDIDO}

A presença de Spinoza na construção do pensamento político-jurídico nos EUA ainda não recebeu a devida atenção, embora alguns fatos forneçam suficientes indícios dessa presença. Uma primeira possibilidade de penetração da filosofia spinozana envolveria o notório conhecimento dos americanos sobre a experiência política dos Países Baixos. O artigo XX do Federalista dedica-se à análise da estrutura política da Confederação dos Países Baixos, de seus acertos e de seus equívocos. Trata-se, na verdade, de uma crítica à forma pela qual a Confederação dos Países Baixos se organizou, forma esta responsável pelas diversas crises experimentadas em razão da inexistência de uma união sólida das repúblicas confederadas. $\mathrm{O}$ texto apresenta elucubraçóes sobre a realidade política dos Países Baixos e sobre as razóes da quase permanente crise vivida pela Confederaçáo, cujo modo de organizaçáo deveria ser evitado. Motivaçáo semelhante levou Spinoza a redigir o Tratado teológico-político e o Tratado político. Tais obras miravam o conhecimento das causas da crise da república dos Países Baixos e, mais especificamente, o Tratado político, um projeto de reforma das instituiçóes 
políticas. ${ }^{3}$ No entanto, nada permite afirmar com certeza o conhecimento da obra de Spinoza, no artigo XX dos Artigos Federalistas.

Outra hipótese de proximidade dos pensadores americanos seria a seguinte: teria chegado aos EUA o conhecimento do projeto político do professor de Spinoza, Van den Enden? Como atesta seu depoimento, às vésperas de seu enforcamento, Franciscus Van den Enden formulou um projeto político para instituir uma "Nova Holanda" na América (ISRAEL, 2001, p. 1830). Tratava-se de projeto voltado à organização de uma república democrática na América do Norte, fundada na igualdade entre todos os cidadáos e entre os sexos, na participação política livre, na proibição da escravidão e na realização do bem comum, inclusive no que se refere à promoção da saúde e da alfabetização gratuitas de todos os cidadãos. ${ }^{4}$ Entretanto, nos debates fundadores dos EUA, não há registro do conhecimento desse projeto, concebido um século antes da eclosão da revolução americana.

Uma terceira alternativa apontaria para a evidente relação entre o pensamento federalista e o pensamento maquiaveliano, fartamente analisado por Pocock, em The Machiavellian moment (POCOCK, 1975, p. 506-552). A presença de Maquiavel na reflexão política spinozana é igualmente importante, embora haja significativas distinçôes entre o pensamento de ambos. No entanto, nos artigos federalistas, a influência de Maquiavel envolve duas questôes: a defesa da necessidade de expansão da fronteira, para garantir a unidade e a prosperidade dos EUA, e a afirmação de uma concepção sobre a política e as instituiçôes baseada da dinâmica passional. Talvez essa última questão pudesse sugerir um indício da presença de Spinoza, todavia, na verdade, ela indica, efetivamente, a presença de Maquiavel no texto.

Apesar de as hipóteses acima revelarem apenas tênues sintomas ou pistas remotas da influência de Spinoza nos EUA, no final do século XVIII, a eliminação desse ponto cego do debate sobre as constituiçóes modernas e a democracia requer a compreensão dessa relação teórica e histórica. Manfred Walther (WALTHER, 1990, p. 292), há muito, apontou para essa direção e identificou alguns elementos capazes de abrir linhas

\footnotetext{
${ }^{3}$ Sobre a concepção spinozana de federação e as semelhanças com alguns elementos forjados nos Artigos Federalistas, ver Gross (1996, p. 117-136).

${ }^{4}$ Sobre a vida e a obra de Franciscus Van den Enden ainda há muito poucas referências. Além da mençấo feita por Jonathan Israel, foi publicada uma recente tradução argentina de sua obra Vrye Politijke Stellingenen Consideratien van Staat (VAN DEN ENDEN, 2010). Há também recentes artigos que esclarecem a natureza das ideias políticas de Van den Enden e sua influência sobre o pensamento de Spinoza (ROCHA; NOGUEIRA, 2010. p. 33-42; TATIAN, 2011; KLEVER, 2012d, 2012c).
} 
de investigação da influência de Spinoza, no debate sobre a fundação da Constituição dos EUA.

Segundo Walther, nos debates fundadores do constitucionalismo norte-americano reside uma decisiva evidência da presença de Spinoza: Thomas Jefferson possuía três obras de Spinoza, em sua biblioteca, a Opera posthuma, a versão em latim do Tratado teológico-político e uma tradução da mesma obra para o inglês (WALTHER, 1990, p. 292-293). Em outras palavras, Jefferson adquiriu todas as obras de Spinoza, ao menos todas as conhecidas até então, na medida em que a correspondência de Spinoza, o Tratado da emenda, a Ética e o Tratado politico compunham a Opera posthuma. Disso se conclui que Jefferson conhecia todas as obras de cunho político de Spinoza: a Ética, o Tratado político e o Tratado teológico-político. Dado o protagonismo de Jefferson, no processo de fundação política e jurídica dos EUA, essa evidência revela que o spinozismo atravessou o Atlântico Norte e aportou nas treze ex-colônias inglesas.

Walther sugere três linhas de investigação sobre a presença de Spinoza, nos debates dos pais fundadores dos EUA: a) as diferentes formas de governo ou de constituição (monarquia, aristocracia, democracia), tema presente nas reflexôes e debates nos séculos XVII e XVIII; b) a questão da federação, abordada por Spinoza no Tratado político e um dos pontos centrais do debate norte-americano; c) o problema da instituiçáo da religiáo civil e de um credo comum, capaz de exercer o papel de mediador e de integrador das distintas formas de expressão religiosa que compuseram o pluralismo religioso dos EUA (WALTHER, 1990, p. 292 - p. 293).

Além dessas questóes mencionadas por Walther, haveria outros pontos de contato? Certamente. Spinoza e autores como Madison, Hamilton, Franklin e Adams representam duas vertentes do iluminismo, o iluminismo radical (Spinoza) e o iluminismo moderado (os demais), conforme tese sustentada pelo historiador Jonathan Israel. De acordo com a tese central desenvolvida e demonstrada em três de suas obras - Radical enlightenment, Enlightenment contested e Democratic enlightenment - o iluminismo não foi um movimento homogêneo e tampouco se estabeleceu em meados do século XVIII, na Europa, em um país e a partir de um autor em especial (ISRAEL, 2006, p. 60). Para Israel, o iluminismo data do século XVII e nasceu em meio a uma disputa que envolvia três tendências e que atravessou toda a Europa: os iluministas radicais, cuja mais perfeita e sofisticada expressão se encontra na obra de Spinoza (ISRAEL, 2001, p. 159-176), os iluministas moderados e os contrailuministas (ISRAEL, 2001, p. 03-22; 2006, p. 43-60). Essa disputa, 
segundo Israel, não apenas percorreu a Europa, mas fincou estacas nas Américas. Tratou-se de disputa paneuropeia e panamericana. Dado o protagonismo de Spinoza, na formação do iluminismo radical, as respostas moderadas, direta ou indiretamente, na maior parte das vezes, decorreram das teses spinozanas, ainda que na forma de refutação, conforme demonstrado acima.

No que se refere ao dissenso entre radicais e moderados, as posiçóes de Thomas Paine e de John Adams refletiram essa tensão, de um lado do Atlântico Norte (ISRAEL, 2011, p. 244-248), tanto quanto as divergências entre Spinoza, exemplar representante das luzes radicais, e Locke e Montesquieu, filósofos da moderação iluminista, a expressaram, do outro lado do Atlântico Norte (ISRAEL, 2001, p. 165 - p. 270) ${ }^{5}$. Paine, em uma de suas últimas obras, The Age of reason, chegou a mencionar explicitamente Spinoza para reforçar seu argumento sobre as Escrituras (PAINE, 2009b, p. 767), estratégia tão difícil quanto rara no século XVIII, quando a proximidade intelectual com Spinoza era motivo de proscrição dos debates públicos. Além disso, valeu-se de citações de Maimônides e de Esdras, retiradas do Tratado teológico-político ${ }^{6}$, para desenvolver suas teses contrárias ao cristianismo (ROBBINS, 1983, p. 140). Ou seja, Spinoza forneceu, diretamente, elementos para a produção intelectual do autor de uma das mais relevantes intervençóes no debate político do período fundador dos EUA, o panfleto Common Sense. Eis um importante sinal da penetração de Spinoza nesse debate e do alcance transatlântico do iluminismo radical.

Spinoza foi também objeto de estudo crítico por parte de um dos pais fundadores, James Madison. Seu professor, John Whitherspoon, um dos grandes adversários de Thomas Paine, costumava usar em suas liçóes as obras de Clarke e de Leibniz (ISRAEL, 2011, p. 452), dois ferrenhos e autênticos refutadores de Spinoza (ROBSON, 1985, p. 65). Certamente por intermédio de Whitherspoon, Madison tomou ainda contato com o pensamento de Bayle (ISRAEL, 2011, p. 458), um crítico e difusor do spinozismo, tendo em vista o papel exercido pelas refutaçóes de Spinoza acima exposto. Bayle contribuiu, decisivamente, para a criação de uma imagem de Spinoza que atravessou o século

\footnotetext{
${ }^{5}$ Jonathan Israel e Wim Klever dissentem sobre a relação entre Locke e Spinoza. Para Israel, sofreu influência de Spinoza, mas moderou seus aspectos radicais. Wim Klever, por sua vez, não percebe sinais de moderação em Locke, que não seria um adversário de Spinoza, mas um seguidor de suas teses. ${ }^{6}$ Há semelhanças evidentes, apontadas por Caroline Robbins, entre os capítulos VII, VIII e IX do Tratado teológico-político e o trecho da segunda parte da obra The Age of reason, a qual trata das contradiçóes do Antigo Testamento. A comparação minuciosa desses dois textos ainda carece de estudo aprofundado.
} 
XVIII e influenciou a interpretação enviesada de sua obra, nesse período ${ }^{7}$, apesar de sua crítica haver difundido o pensamento de Spinoza entre aqueles que não possuíam acesso direto a sua obra, em razão das dificuldades de sua circulação.

Thomas Jefferson, conforme exposto acima, um dos protagonistas do processo de fundação dos EUA, certamente também se relacionou com a filosofia de Spinoza. Dois fatos comprovam o conhecimento de Spinoza por Jefferson: as já mencionadas aquisiçóes do Tratado teológico-politico e da Opera posthuma e as influências de Bolingbroke (JAYNE, 1998, p. 19-40) ${ }^{8}$, cujo pensamento foi decisivo na formação de Jefferson sobre a questão religiosa. A posição crítica de Bolingbroke sobre o milagre se assemelha ao raciocínio de Spinoza. Os milagres, tanto para um quanto para outro, mais negam a onipotência divina do que propriamente a afirmam. Além disso, Bolingbroke defendia que temos tanto mais conhecimento de Deus quanto mais conhecemos as leis que governam o mundo (JAYNE, 1998, p. 23-24). Nesse sentido, os milagres, na medida em que rompem com essas leis, nos levariam à ignorância, e não ao conhecimento de Deus (ISRAEL, 2011, p. 457). ${ }^{?}$

\section{A Declaração de IndependênCIA dos EUA: SERIAM Locke E JEFFerson SPINOZISTAS?}

Antes de enfrentar a questão proposta, é preciso percorrer certos elementos biográficos, para demonstrar a relação entre Locke e Spinoza. Locke viveu um período de cinco anos de exílio, em Amsterdam, entre 1683 e 1688. A morte de Spinoza, em 1677, coincidiu com a publicação de sua Opera posthuma. Em razão da proximidade temporal entre a publicação da

\footnotetext{
${ }^{7}$ Sobre a relação entre Bayle e Spinoza, ver Chauí (2009).

${ }^{8}$ Em sua correspondência, Jefferson explicita sua admiraçăo por Bolingbroke, em missiva endereçada a Francis Eppes, em 19 de janeiro de 1821. Eis a passagem sobre Bolingbroke: "He was called indeed a tory; but his writings prove him a stronger advocate for liberty than any of his countrymen, the whigs of the present day [...] Lord Bolingbroke's, on the other hand, is a style of the highest order. The lofty, rhythmical, full-flowing eloquence of Cicero. Periods of just measure, their members proportioned, their close full and round. His conceptions, too, are bold and strong, his diction copious, polished and commanding as his subject. His writings are certainly the finest samples in the English language, of the eloquence proper for the Senate. His political tracts are safe reading for the most timid religionist, his philosophical, for those who are not afraid to trust their reason with discussions of right and wrong." (JEFFERSON, 2011, p. 1451).

9 Segundo Jonathan Israel, existe uma discussão sobre as influências nas quais Bolingbroke haveria encontrado inspiração, para defender essas teses. Há duas hipóteses: ou bem Spinoza ou bem Toland e Collins se encontrariam na origem do raciocínio de Bolingbroke. No entanto, é certo que, embora a influência imediata não seja de Spinoza, há um evidente spinozismo no raciocínio de Bolingbroke.
} 
Opera posthuma e o período de exílio, é razoável supor o conhecimento das teses de Spinoza.

Os contemporâneos de Locke, por sua vez, perceberam em sua filosofia elementos de natureza spinozana. Leibniz, por exemplo, acreditava que Locke era uma mera imitação de Spinoza (KLEVER, 2012a, p. 62). Por outro lado, William Carroll atribuiu a Locke a responsabilidade pela difusão dissimulada das hipóteses spinozanas. Carroll, inclusive, nadou contra a corrente da tendência inglesa de associação entre o platonismo e Spinoza e acusou Spinoza e Locke de materialismo (ELLENZWEIG, 2003, p. 393). Não apenas os adversários de Locke reconheceram elementos spinozistas em seu pensamento. Um de seus amigos próximos, Pierre des Maizeaux, confidenciou a Jean Barbeyrac a filiação de Locke à tese da unicidade substancial, uma das teses spinozanas mais atacadas (KLEVER, 2012a, p. 63).

Apesar dessas evidências biográficas da presença do spinozismo na filosofia de Locke, Spinoza permaneceu na posição de sujeito oculto da história das ideias do mundo anglo-saxão. Trata-se de um verdadeiro elo perdido, segundo Manfred Walther (WALTHER, 2007, p. 306). Certamente, essa ausência se deve a uma muito difundida, entre os anglo-saxôes, oposição entre racionalismo e empirismo, que seria a origem de uma outra oposição, entre continentais e não-continentais (ou analíticos). Segundo Walther, o papel metodológico conferido por Spinoza à experiência permite aproximá-lo de Locke, da mesma forma que a afirmação lockeana de que o espírito é capaz de construir ideias complexas por seu próprio poder conduz Locke às vizinhanças do pensamento de Spinoza (WALTHER, 2007, p. 307). Manfred Walther, portanto, demonstra que o corte rígido instituído, por certas linhagens da história das ideias, entre empiristas e racionalistas não é tão claro e preciso, quando nos aproximamos dos textos desses dois autores. A rigor, há elementos de racionalismo e de empirismo em ambos.

Conforme Walther, outros exemplos ajudam a borrar as rígidas linhas resultantes do esforço de separação do racionalismo de Spinoza e do empirismo de Locke. Além do exemplo acima, há outros dois casos de proximidade entre Spinoza e Locke: a) o desejo em Locke seria um equivalente do conatus de Spinoza, pois os estados da alma fundamentais variam segundo o desejo, para Locke, e de acordo com o conatus, para Spinoza; b) a subordinação da vontade ao desejo, proposta por Locke, representa mais um indício de que sua filosofia é banhada de influências spinozanas (WALTHER, 2007, p. 307). 
Diante dessas evidências da apropriação, por Locke, de elementos do pensamento de Spinoza e da notória influência de Locke sobre Thomas Jefferson, surgem necessariamente duas questóes: essa absorção lockeana do spinozismo reverberou no texto da Declaração de Independência dos EUA? Seria Jefferson um spinozista inconsciente? Dois elementos da Declaração, nitidamente de origem lockeana, permitem responder afirmativamente a essas questôes: a) a noção de "verdade autoevidente" (self evident truths); b) o direito à busca da felicidade. ${ }^{10}$

A origem da noção de verdade autoevidente, mencionada por Jefferson na Declaração, encontra-se em um dos graus de conhecimento lockeanos: o conhecimento intuitivo. Tal forma de conhecimento envolve uma apreensão imediata da distinção entre duas ideias, sem necessidade de qualquer outra ideia e, portanto, do modo demonstrativo de conhecimento (LOCKE, 1997, p. 471-472). Eis a inspiração de Jefferson, ao elaborar a Declaração de Independência. ${ }^{11}$ A concepçáo de intuição proposta por Locke se aproxima consideravelmente da definição spinozana de intuição, que também diz respeito a um modo de percepção instituído de um só golpe de vista, sem mediação da razão (SPINOZA, 2007, Parte II, Proposição 40, Escólio 2). Além disso, a intuição, conhecimento adequado que é, exprime verdades autoevidentes, pois, para Spinoza, "[...] quem tem uma ideia verdadeira sabe, ao mesmo tempo, que tem uma ideia verdadeira, e não pode duvidar da verdade da coisa." (SPINOZA, 2007, Parte II, proposição 43).

A busca da felicidade, outro elemento lockeano de grande destaque na Declaração de Independência (JAYNE, p. 128-138), assinala mais um ponto de contato entre Locke e Spinoza, pois a noção de felicidade de Locke possui contornos muito semelhantes à noção de alegria spinozana. Segundo Locke, a felicidade é a forma mais perfeita de prazer, enquanto a tristeza, a forma mais expressiva de dor (LOCKE, 1997, II, 21, \$42). O prazer e a dor definem as noçôes de bem e de mal. Bom, portanto, é o que nos causa prazer. Por sua vez, mau é o que provoca dor (LOCKE, 1997, II, 20, \$2). Disso se conclui que a felicidade é o bem supremo.

\footnotetext{
${ }^{10}$ Haveria, ainda, um terceiro elemento spinozano, herdado por Locke e presente na Declaração: a conservação do direito natural e coletivo de resistir à opressão. Neste trabalho, no entanto, analisaremos apenas os dois primeiros, visto que a demonstração da presença do conceito de direito de resistência spinozano, no pensamento de Locke, demandaria uma longa exposição e uma detalhada explicaçáo do pensamento político dos dois autores, o que tornaria este artigo por demais extenso. Trata-se de tarefa para um artigo específico.

${ }^{11}$ É importante registrar a discordância de Allen Jayne a esse respeito. Para Jayne, a inspiração de Jefferson seria mais Kames do que Locke. Ver Jayne (1998, p. 109-120).
} 
As ideias lockeanas parecem diretamente retiradas da Ética de Spinoza. $\mathrm{Na}$ visão de Spinoza, bom é o que produz alegria e mau o que causa a tristeza (SPINOZA, 2007, Parte IV, Proposição 8 e Proposição 41). Além disso, Locke entende que a busca pela felicidade constitui o verdadeiro fundamento da liberdade (LOCKE, 1997, II, 21, \$51), afirmação que certamente inspirou Jefferson. Da mesma maneira, para Spinoza, a liberdade é indissociável da alegria. O homem livre é aquele capaz de combater as tristezas e estimular as alegrias.

Em suma, percebe-se, na Declaração de Independência, a reverberação do spinozismo herdado por Locke e, provavelmente de modo inconsciente, incorporado por Jefferson. Trata-se de um dos múltiplos efeitos de ressonância que a obra de Spinoza provocou no século XVIII.

\section{O iluminismo radical nos EUA: Thomas Paine, a igualdade E a PROPRIEDADE.}

Além das influências pessoais que puseram Jefferson, Paine e Madison em contato com a filosofia de Spinoza, outro fato concernente à penetração de Spinoza nos EUA, a tensão entre iluminismo radical e iluminismo moderado, marcou sua presença nos debates fundadores dos EUA. A presença do spinozismo nos EUA também ocorreu por meio da incorporação do conflito europeu entre os diferentes iluminismos, na medida em que, no século XVIII, o spinozismo inspirou a construção dos argumentos e do raciocínio do iluminismo radical.

Uma das questóes centrais, senão a questão central, do dissenso entre moderados e radicais foi a igualdade e, consequentemente, a democracia. Nas raízes do republicanismo democrático, movimento vinculado ao iluminismo radical, encontrava-se a rejeição ao governo misto (ISRAEL, 2006, p. 244), ou seja, qualquer governo que buscasse realizar uma conciliação entre monarquia, aristocracia e democracia. ${ }^{12}$

\footnotetext{
${ }^{12} \mathrm{O}$ caso exemplar de Franciscus Van den Enden (ISRAEL, 2001, p. 175-184), professor de Spinoza, e sua rejeição incondicional ao governo misto é um marco para compreender a essência do projeto político do radicalismo iluminista. Van den Enden defendeu incondicionalmente a promoçáo da igualdade e da justa distribuição da propriedade. Essa defesa apontava para as seguintes pautas: democratizaçáo das instituiçôes políticas e extinção de qualquer mecanismo de organizaçâo institucional de natureza monárquica ou aristocrática; equitativa divisão do trabalho, que levasse todos os homens a servirem e serem servidos (VAN DEN ENDEN, 2010, p. 63); redução do tempo dedicado a ofícios bestiais e obrigação de dedicação a ofícios que combatam a ignorância (VAN DEN ENDEN, 2010, p. 108); adequada remuneração do trabalho e proibição de remuneraçôes miseráveis (VAN DEN ENDEN, 2010, p. 55). A pauta de reivindicações da obra de Van den Enden não se esgotava nesses direitos.
} 
A questão da igualdade foi tema de debate permanente, durante o processo de fundação do EUA, embora as questôes sociais não hajam prosperado naquele momento e as questóes políticas tenham ocupado mais espaço nesse debate. Houve um radicalismo político profundo do processo revolucionário americano, posteriormente mitigado, sobretudo no momento de instituiçấo do modelo constitucional dos EUA. A esse radicalismo se vinculou a ideia de igualdade, causa eficiente das significativas mudanças experimentadas nos EUA, desde o final do século XVIII até meados do século XIX. A igualdade, a mais potente e mais radical dentre as ideias do período revolucionário, mobilizou a transformaçáo dos EUA nesse período (WOOD, 1991, p. 239). Conforme explicitado na Declaração de Independência, o processo revolucionário imprimiu uma marca perene na consciência comum dos EUA. Todos os homens nasciam iguais e na igualdade repousava o fundamento da independência. A autonomia individual pressupunha a igualdade, tanto de oportunidades quanto de condiçóes. Ao estabelecer que "[...] todos os homens eram criados iguais e independentes", no rascunho da Declaração, Jefferson simplesmente sintetizou o autêntico espírito revolucionário (WOOD, 1991, p. 234). A condição humana, da Declaração em diante, envolvia a igualdade. O fundamento de nenhuma distinção de nascimento, de propriedade, de talento ou de religião subsistiu, a partir da Declaração de Independência.

A obra de Thomas Paine representou um dos marcos de afirmação da igualdade, da defesa da democracia e da incondicional crítica à monarquia e à aristocracia (PAINE, 2009c, p. 478-480). Segundo Paine, as repúblicas se mostravam mais adequadas às circunstâncias do final do século XVIII. Além disso, propiciavam melhores condiçóes à garantia da paz, tanto que até os Países Baixos, cuja república, na opinião de Paine, fora mal instituída, conservaram por mais de um século a paz (PAINE, 2009c, p. 539). A monarquia e as cortes que normalmente a cercam já apresentavam sinais de decadência e, consequentemente, a prudência recomendava sua ampla e irrestrita abolição.

Além da organização institucional democrática, da divisão social do trabalho, da organização do tempo do trabalhador e da defesa de remuneraçóes dignas, Van den Enden propôs direitos que tocavam diretamente na distribuição da propriedade. Por exemplo, Van den Enden defendia a suspensão de cobrança de impostos a trabalhadores pobres (VAN DEN ENDEN, 2010, p. 107), a instituição de um projeto de educação pública (VAN DEN ENDEN, 2010, p. 59 e 108) e de saúde pública, mediante a proibiçáo do exercício privado da medicina e do pagamento, pelo Estado, dos salários dos médicos (VAN DEN ENDEN, 2010, p. 59). Ou seja, Van den Enden enfrentou, em sua obra, a questâo da distribuição da propriedade monetária, do saber formal e da propriedade sobre a gestão da saúde. A filosofia política de Spinoza endossa a defesa da igualdade, proposta por Van den Enden, ainda que não se oponha às monarquias e aristocracias, desde que elas contenham elementos institucionais capazes de reformá-las e inseri-las em um processo de progressiva democratização e de promoção da igualdade. 
A sensatez exigia que se antecipassem os movimentos revolucionários e fossem instituídas modificações na ordem política e social, a fim de evitar as convulsôes provocadas pelas revoluçôes. Em certa medida, Paine reproduziu a posição de Spinoza, exposta no Tratado teológico-político e no Tratado político ${ }^{13}$, de que era mais salutar a reforma profunda das instituições e a promoção institucional das exigências revolucionárias do que a eclosão das convulsóes sociais (ISRAEL, 2010, p. 100). Tendo em vista que a publicação da obra The rights of man, na qual Paine apresentou tal conselho, se deu três anos antes da obra The Age of reason, que continha explícitas menções ao Tratado teológico-politico, é admissível considerar que Paine absorvera, diretamente do pensamento político de Spinoza, essa proposta singular de reforma institucional. Trata-se de uma reforma de inspiraçáo revolucionária, contudo, de certo modo, conservadora, pois visa a evitar a convulsão social.

Paine também defendia concepçôes de igualdade concernentes à propriedade que convergiam com as teses spinozanas. Para Paine, a propriedade não resulta de um esforço individual, mas coletivo. Portanto, a aquisição de propriedade não fornece um índice de distinção entre os homens quanto a seu talento ou aptidáo. A propriedade funda-se na potência comum da sociedade, e não na potência do indivíduo. Por essa razão, quanto mais for a propriedade submetida à potência comum, mais segurança adquirimos. Note-se que náo se trata de um discurso contra a propriedade, porém, de uma defesa da necessária distribuição da mesma.

Tal posição se encontra em uma carta datada de fevereiro de 1788 , destinada a Thomas Jefferson (PAINE, 2009a, p. 368-369), na qual o autor distingue os direitos naturais dos direitos civis, em razão de os direitos naturais

\footnotetext{
${ }^{13}$ No Tratado teológico-politico, embora reconheça que a democracia é a forma mais natural de governo, Spinoza recusa as soluçốes voluntaristas para a reorganização institucional. Para Spinoza, um considerável perigo ronda as rupturas abruptas, mesmo quando resultam em eliminação do tirano: a permanência das causas da tirania (SPINOZA, 2003, Capítulo XVII, p. 277). Essa permanência pode provocar o aumento da violência tirânica, pois o governante que assume o lugar do tirano, guiado pelo medo de sofrer o mesmo destino de seu antecessor, usa a violência, preventivamente, para conter a multidão e possíveis convulsōes sociais (SPINOZA, 2003, Capítulo XVIII, p. 284). O problema das rupturas recebe um tratamento de outra ordem, no Tratado político. Se o Tratado teológico-político se debruça sobre os possíveis males das convulsôes sociais, o Tratado político tanto demonstra que a ruína do Estado se encontra na indignação da multidão, cuja potência funda o poder do Estado (SPINOZA, 2009, Capítulo III, 9 e Capítulo IV, 10), quanto expôe uma proposta de reforma institucional orientada pela instituição de um processo democratização do Estado (SPINOZA, 2009, Capítulos VI a IX). Esse processo visa a evitar a indignação da multidão e a preservar as instituiçôes às quais a multidão se habituou, desde que essas instituiçôes se submetam ao permanente processo de afirmação da potência da multidão e de seu desejo de governar e de não ser governada.
} 
dependerem, exclusiva e integralmente, do poder individual. Tudo o que o indivíduo puder realizar plenamente e perfeitamente, mediante seu esforço, é naturalmente direito seu. A liberdade de pensamento, de expressão, de opiniáo e todos os demais direitos exercidos pelos indivíduos, sem necessidade de auxílio externo, constituem os direitos naturais. Já os direitos civis requerem auxílio mútuo para seu exercício. O direito de proteção pessoal e o direito de aquisição e de conservação da propriedade se enquadram nessa categoria. Esses direitos se fundam em um direito concedido ao poder constituído por uma condensação de todas as partes constituintes. Segundo Paine, "[...] em um caso (direitos naturais), nós agimos integralmente em nosso próprio nome, enquanto no outro caso (direitos civis) nós concordamos não agir em nosso próprio nome, mas sim agir sob o aval da sociedade." (PAINE, 2009a, p. 368, tradução livre). A concepção da origem da propriedade, exposta na missiva dirigida a Jefferson, certamente possui raízes históricas no movimento de conquista comum do território empreendido pelos cidadãos americanos, no qual a experiência coletiva de alargamento das fronteiras instituiu a propriedade, $\mathrm{e}$ não a aquisição individualista. Do ponto de vista conceitual, a posição de Paine coincide quase literalmente com a de Spinoza, no Tratado teológico-político, no qual Spinoza distingue os direitos exercidos por necessidade pelos indivíduos, como a liberdade de pensamento e de opinião (SPINOZA, 2003, p. 310), e aqueles que dependem da instituição de uma potência comum. Quanto a esses últimos, que Paine define por direitos civis, Spinoza (2003, p. 237) entende que "[...] para viver em segurança e o melhor possível, os homens tiveram forçosamente de unir-se e fazer assim com que o direito natural que cada um tinha sobre todas as coisas se exercesse coletivamente e fosse determinado [...] pelo poder e pela vontade de todos em conjunto." Essa passagem traduz com perfeição a ideia de Paine de que a propriedade é fruto de um poder constituído pelos indivíduos. Quanto mais a propriedade é submetida à vontade de todos, em conjunto, maior a segurança e maior a estabilidade do Estado.

$\mathrm{O}$ radicalismo das ideias de Thomas Paine atingiu ainda a questão social. Em sua obra The rights of man, existe uma defesa firme de um projeto de educação gratuita das crianças de famílias pobres e de assistência social de idosos, mediante pagamento de pensóes e de uma proposta de reorganização tributária e orçamentária de caráter redistributivo (PAINE, 2009c, p. 625-643). Ou seja, Paine, em 1792, propôs o uso da política tributária para promoção de justiça social, o que, muito posteriormente, seria implementado pelo welfare state. 
5 O Iluminismo moderado nos EUA: federalistas, Montesquieu E a ALTERNATIVA AO RADICALISMO

O iluminismo radical, no entanto, não alcançou hegemonia durante o processo de instituição da ordem político-jurídica nos EUA. Mesmo Thomas Jefferson (ISRAEL, 2011, p. 457) ${ }^{14}$, cuja Declaração de Independência se apoiou em teses do iluminismo radical, fez concessôes à tendência moderada do iluminismo. Três foram os sinais evidentes da vitória moderada: a instituição de um executivo forte, cuja finalidade deliberada era conter a tendência democrática da revolução americana (ISRAEL, 2010, p. 44); o estímulo à formação de uma aristocracia informal, nos EUA (ISRAEL, 2010, p. 44, 46); a adoção de um modelo de constituição mista, inspirada na constituição inglesa, com as devidas e necessárias adaptaçôes para um governo republicano que não mais admitia a hereditariedade por método de sucessão e que, consequentemente, recusava a explicitação da distinção de classe, na composição das duas câmaras do legislativo.

$\mathrm{O}$ apreço pela constituição inglesa explica a grande influência de Montesquieu, durante o processo de elaboração da constituição dos EUA. Essa influência consistiu, igualmente, em um meio de penetração - ainda que crítica, pois Montesquieu rejeitava a perspectiva democrática spinozana - do pensamento político de Spinoza. A incorporação das teses de Montesquieu, portanto, demonstra de que maneira a resposta moderada ao problema da instituição do poder, em sociedades modernas, derrotou a proposta do iluminismo radical, cunhada no século XVII por Spinoza, por Van den Enden e desenvolvida pelo spinozismo do século XVIII. É importante, de início, compreender a relaçáo de Montesquieu e de Spinoza, para entáo entender a moderação das algumas teses spinozanas, proposta por Montesquieu.

Montesquieu, provavelmente, tomou ciência do pensamento político de Spinoza e, indubitavelmente, do spinozismo do século XVIII. ${ }^{15}$ De acordo com Paul Vernière, vários são os aspectos da obra de Montesquieu a refletir influências spinozanas. A crítica aos milagres, a inerência do movimento à matéria, a definição de lei como uma relação necessária derivada da natureza das coisas e a tendência do ser em perseverar configuram, para Vernière (1954 p. 447-466), evidências inegáveis dos vínculos entre Montesquieu e Spinoza.

\footnotetext{
${ }^{14}$ Segundo Jonathan Israel, Jefferson era um exemplo da tensão entre iluminismo radical e iluminismo moderado, nos EUA. Sua obra consistiria em uma tentativa de síntese entre ambos.

15 Sobre os documentos que sinalizam o conhecimento de Spinoza por Montesquieu, ver VolpilhacAuger (2007, p. 389-397). Esse texto também registra a amizade de Montesquieu com Boulainvilliers, que foi responsável pela primeira tradução francesa da Ética.
} 
Yves Citton (2006, p. 54), por sua vez, adota postura mais cautelosa. Para ele, Montesquieu, cuja obra era excessivamente moderada para ser considerada spinozana, náo teria praticado o spinozismo e talvez sequer tenha lido a obra de Spinoza em detalhes. No entanto, Citton (2006, p. 54) reconhece que o texto $A$ defesa do espírito das leis é um caso exemplar dos efeitos de ressonância da difusão do spinozismo e exprime conhecimento de alguns aspectos do pensamento de Spinoza, sobretudo daquilo que significava "ser spinozista", em meados do século XVIII. No entanto, tais efeitos de ressonância náo foram suficientes para impedir que a obra de Montesquieu, na qual há uma clara aposta na prudência aristocrática contra a desmedida democrática, considerada despótica por Montesquieu, se estabelecesse como resposta à alternativa democrática spinozista.

Já Jonathan Israel, assim como Vernière, é taxativo: Spinoza influenciou Montesquieu, embora o antagonismo, e não a convergência, defina melhor sua relação com Spinoza (ISRAEL, 2006, p. 287-294). A proposta de governo moderado, fundado na prudência aristocrática e na garantia da unidade pela monarquia, consistiu em uma alternativa ao iluminismo radical e à sua ramificação política, o republicanismo democrático, linhagem na qual Spinoza possui posição de notório protagonismo (ISRAEL, 2001, p. 175-180). O projeto de Montesquieu se caracterizou por oferecer uma alternativa liberal-aristocrática ao republicanismo democrático e igualitário e se tornou influência decisiva para os federalistas, os quais, é sempre bom lembrar, precisavam enfrentar o debate da aristocracia natural nos EUA do final do XVIII e tomar uma posição entre sua substituição ou sua restauração, como registra Pocock (1975, p. 517).

Apesar do antagonismo entre Spinoza e Montesquieu, o barão francês, um "tenor das Luzes", segundo expressão de Yves Citton (2006, p. 54), representou um dos canais pelos quais Spinoza chegou até os debates fundadores dos EUA e, notoriamente, foi referência de primeira grandeza para os pais fundadores. Aliás, Hannah Arendt, em Sobre a revolução (ARENDT, 2011, p. 198-199), talvez não sem discordância da leitura maquiaveliana de Pocock acerca da revolução americana, expóe a opinião de que Montesquieu estaria para a revolução americana assim como Rousseau esteve para a revolução francesa. Não por acaso, os federalistas mencionam Montesquieu em momentos críticos do texto, aliás, talvez nos dois momentos mais críticos da obra. O primeiro deles, o artigo IX, buscou defender a reforma da partilha territorial do poder, que substituiu a Confederação das treze ex-colônias in- 
glesas e pôs em seu lugar a Federação dos Estados Unidos da América. O livro IX de $O$ espirito das leis é citado nesse artigo, no qual se reproduz longo trecho da obra. A penetração indireta de Spinoza, no discurso dos federalistas sobre a federação, possivelmente aconteceu, porque o argumento desenvolvido por Montesquieu para defesa da federação é idêntico ao apresentado por Spinoza, no Tratado político (SPINOZA, 2009, Capítulo IX). Essa identidade, inclusive, demonstra que, mesmo vitorioso, o iluminismo moderado não recusava de todo as teses do iluminismo radical, pois absorveu determinadas teses de seus contendores radicais.

No artigo XLVII, os federalistas mencionam novamente Montesquieu, não mais para justificar a união entre os Estados, mas para a defesa do modelo de separação de poderes e de governo moderado proposto em $O$ espirito das leis. A moderação proposta por Montesquieu afirma a prevalência do princípio aristocrático, a fim de limitar os excessos democráticos e o despotismo de matriz monárquica. A separação de poderes nos EUA reproduziu essa prevalência e instituiu uma espécie de aristocracia natural, representada por duas instituiçôes: o Senado e a Suprema Corte. Os anseios populares, oriundos da câmara baixa, deviam sofrer moderação da câmara alta, o Senado, cuja eleiçáo, na origem do projeto constitucional dos EUA, ocorria indiretamente. Já as decisôes monocráticas do poder executivo presidencial, cuja força remete à monarquia, se houvesse questionamento quanto a sua validade, dependiam do crivo da Suprema Corte. A natureza aristocrática desse órgão judicial se comprova por duas razóes: seus membros não são eleitos até hoje e devem demonstrar notável conhecimento jurídico, para exercer o cargo de juiz da Suprema Corte. Em suma, o sistema de separação de poderes dos EUA adaptou, ao contexto norte-americano, a proposta de moderação aristocrática dos anseios populares, de um lado, e das decisóes monárquicas, de outro.

Em suma, o projeto iluminista moderado, cunhado por Montesquieu e de inspiração aristocrática, exerceu relevante influência na proposta reformista dos federalistas, para instituição da separação de poderes e organização do sistema de freios e contrapesos e visava a instituir uma república capaz de conter os anseios populares. Nesse caso, o iluminismo moderado ocupou evidente posição de antagonismo em relação ao projeto constitucional spinozano, símbolo fundamental da tendência republicana democrática do iluminismo radical, ao lado da obra de seu professor Van den Enden e dos Discursos de Maquiavel. 


\section{CONCLUSÃo}

Diante das evidências apresentadas e analisadas, ao longo deste trabalho, é possível afirmar que, de fato, Spinoza chegou aos EUA e, direta ou indiretamente, influenciou os debates públicos ocorridos entre o período pré-revolucionário e a década posterior à fundação constitucional da federação norte-americana. Além disso, as disputas entre iluministas radicais e moderados, as quais também atingiram os EUA, nesse período, levaram os conceitos e os temas abordados por Spinoza para o outro lado do Atlântico Norte.

Há, ainda, uma série de temas a investigar, para futuras análises da penetração de Spinoza nos EUA, que este artigo não se propôs enfrentar, visto que demandaria um rigoroso e minucioso trabalho de análise conceitual e, consequentemente, um ou mais artigos que se debruçassem sobre tais temas. A questão do direito de resistência, abordada na Declaração de Independência, o problema da formação de uma religião civil e da garantia da tolerância religiosa e a reflexão sobre a instituição da federação são três exemplos de temas não aprofundados neste artigo, os quais podem conter elementos da filosofia de Spinoza.

GUIMARAENS, F. Spinoza: the hidden subject in the disputes between followers of the radical and the moderate Enlightenment in the founding of the United States. Trans/form/ ação, Marília, v. 41, n. 1, p. 141-162, Jan./Mar., 2018.

\footnotetext{
ABSTRACT: This paper examines a question that has been not often been discussed by those who study the process of the founding of the United States during the last decades of the 18th century. The investigation involves the influence of Spinoza on the political debates of this period. Jonathan Israel's distinction between the radical and the moderate Enlightenment will guide the argument presented here, because Israel indicates that Spinoza was an important reference for the radical thinkers. The conflict between adherents to the radical and the moderate Enlightenment was present before and after the United States' independence.
}

KEYwords: Spinoza, Enlightenment, United States Constitution. 


\section{REFERÊNCIAS}

ARENDT, H. Sobre a revolução. São Paulo: Companhia das Letras, 2011.

CHAUI, M. A estrutura retórica do verbete Spinoza. Kriterion: Revista de Filosofia, Belo Horizonte, v. 50, n. 09, dez. 2009. Disponível em: http://www.scielo.br/scielo. php?pid=S0100-512X2009000200001\&script=sci_arttext. Acesso em: 14 out. 2015.

CITTON, Y. L'envers de la liberté: L'invention d'um imaginaire spinoziste dans la France des Lumières. Paris: Éditions Amsterdam, 2006.

. L'invention du spinozism dans la France du XVIIIe. Siècle. In: SECRÉTAN, C.; DAGRON, T.; BOVE, L. Qu'est-ce que les lumières "radicales"? Libertinage, athéisme et spinozisme dans le tournant philosophique de l'âge classique. Paris: Éditions Amsterdam, 2007. p. 309-324.

DELEUZE, G. Nietzsche e São Paulo, D. H. Lawrence e João de Patmos. In:

Crítica e clínica. São Paulo: Editora 34, 2004. p. 45-63.

ELLENZWEIG, S. The love of God and the radical enlightenment: Mary Astell's Brush with Spinoza. Journal of the History of Ideas, v. 64, n. 03, p. 379-397, jul. 2003.

ISRAEL, J. Radical enlightenment: philosophy and the making of modernity 1650 1750. Oxford: Oxford University Press, 2001.

Enlightenment contested: philosophy, modernity and the emancipation of man, 1670 - 1752. Oxford: Oxford University Press, 2006.

. A revolution of the mind: radical enlightenment and the intellectual origins of modern democracy. New Jersey: Princeton University Press, 2010.

. Democratic enlightenment: philosophy, revolution and human rights 1750 -1790. Nova Iorque: Oxford University Press, 2011.

JAYNE, A. Jefferson's Declaration of Independence: origins, philosophy and theology. Lexington: The University Press of Kentucky, 1998.

JEFFERSON, T. Jefferson writings. Nova Iorque: The Library of America, 2011.

KLEVER, V. Locke's disguised spinozism (part 1). Revista Conatus: Filosofia de Spinoza, Fortaleza, v. 6, n. 11, p. 61-82, jul. 2012a.

. Locke's disguised spinozism (part 2). Revista Conatus: Filosofia de Spinoza, Fortaleza, v. 6, n. 12, p. 53-64, dez. 2012b.

. Conflicting "consideration of state". Van den Enden's opposition against de La Court's aristocratic republicanism and its follow-up in Spinoza's work. Disponível em: <http://www.fogliospinoziano.it/artic17b.htm>. Acesso em: 02 fev. 2012c.

. Imperium aeternum: Spinoza's critique of Machiavelli and its source in Van den Enden. Disponível em: <http://www.fogliospinoziano.it/artic14.htm>. Acesso em: 02 fev. 2012d. 
LOCKE, J. An Essay concerning human understanding. Londres: Penguin Books, 1997.

PAINE, T. To Thomas Jefferson. In: . Collected writings. Nova Iorque: The Library of America, 2009a.

. The Age of reason. In: . Collected writings. Nova Iorque: The Library of America, 2009b.

- The rights of man. In: . Thomas. Collected writings. Nova Iorque: The Library of America, 2009c.

POCOCK, J. G. A. The Machiavellian moment: florentine political thought and the Atlantic republican tradition. Princeton: Princeton University Press, 1975.

ROBBINS, C. The lifelong education of Thomas Paine (1737-1809): some reflections upon his acquaintance among books. Proceedings of the American Philosophical Society, v. 127, n. 3, p. 135-142, 1983.

ROBSON, D. W. Educating republicans: the college in the era of American revolution 1750-1800. Westport: Greenwood, 1985.

ROCHA, M.; NOGUEIRA, D. Franciscus Van den Enden: Ex-jesuíta, poeta, médico, comerciante de arte, filósofo e político, professor de Spinoza, encenador de comédias latinas, conspirador contra Luís XIV. In: TATIAN, D. (Org.). Spinoza, sexto colóquio. Córdoba: Brujas, 2010. p. 33-42.

SPINOZA, B. Tratado teológico-político. São Paulo: Martins Fontes, 2003. . Ética. Belo Horizonte: Autêntica, 2007. . Tratado político. Sáo Paulo: Martins Fontes, 2009.

TATIAN, D. Quien más ama las cosas: radicalismo democrático y libertad igualitaria en Francis Van den Enden. In: Colóquio sobre republicanismo e democracia: homenagem a Professora Marilena Chaui. 2011. São Paulo, USP. (mimeo.).

VAN DEN ENDEN, F. Libertad politica y Estado. Buenos Aires: El Cuenco de Plata, 2010. VERNIÈRE, P. Spinoza et la pensé française avant la révolution. Paris: Presses Universitaires de France, 1954.

VOLPILHAC-AUGER, C. Une modération radicale? Montesquieu. In: SECRÉTAN, C.; DAGRON, T.; BOVE, L. Qu'est-ce que les lumières "radicales"? Libertinage, athéisme et spinozisme dans le tournant philosophique de l'âge classique. Paris: Éditions Amsterdam, 2007. p. 389-396.

WALTHER, M. Negri on Spinoza. In: CURLEY, E.; MOREAU, P.-F. (Ed.). Spinoza issues and directions: the proceedings of the Chicago Spinoza Conference. Leiden: E. J. Brill, 1990. p. 286-297. 
GUIMARAENS, F.

Spinoza et les lumières radicales: quelques observations à propos de trois thèses de Jonathan Israel. In: SECRÉTAN, C.; DAGRON, T.; BOVE, L. Qu'est-ce que les lumières "radicales"? Libertinage, athéisme et spinozisme dans le tournant philosophique de l'âge classique. Paris: Éditions Amsterdam, 2007. p. 299-308.

WOOD, G. S. The radicalism of the American revolution. Nova Iorque: Vintage Books, 1991.

Recebido: 16/02/2016

Aceito: $27 / 07 / 2016$ 